\title{
Variables socioeconómicas y apoyo a la democracia en Chile, Perú y Colombia: la pobreza como factor clave
}

\author{
Socio-economic variables and democratic support in Chile, Peru and \\ Colombia: Poverty as the key factor
}

Iván Alejandro Valdés Gutiérrez

Recibido: 2 de septiembre de 2013. Aprobado: 15 de junio de 2015

\begin{abstract}
Resumen
El presente artículo establece la relación entre un número de variables económicas y sociales -crecimiento, pobreza, desigualdad, Índice de Desarrollo Humano (IDH) y gasto público- y la evolución de los índices de apoyo ciudadano a la democracia, durante el período que va de 2000 a 2011. Todo, comparando los resultados entre tres países latinoamericanos: Chile, Perú y Colombia. La interpretación se hizo a partir del enfoque de las llamadas teorías del desarrollo. Los resultados arrojan que en el largo plazo existe relación entre pobreza, IDH y apoyo declarado a la democracia entre la población.
\end{abstract}

Palabras claves: desarrollo, democracia, pobreza.

\begin{abstract}
This article assess the relationship between numbers of economic and social variables -growth, poverty, inequality, Human Development Index (HDI) and public expenditureand the evolution of citizens' support to democracy index between the period 20002011. The results of the relationship of these indicators are compared between three Latin American countries: Chile, Peru and Colombia. The interpretation was done from devel-

Periodista y Licenciado en Comunicación Social de la Universidad de Chile; Máster en Relaciones Internacionales por la Universidad Complutense de Madrid; y Máster en Estudios Latinoamericanos por la Universidad de Barcelona. Correo electrónico: ivanvalde@gmail.com
\end{abstract}


opment theories frameworks. The final results show that in long run there is a positive relationship between poverty, IDH and citizens' support to democracy.

Keywords: development, democracy, poverty.

\section{Introducción}

El presente trabajo tiene como objetivo establecer la relación entre indicadores socio-económicos y la valoración de los ciudadanos sobre la democracia, en tres países sudamericanos: Chile, Perú y Colombia. Los indicadores a usar son: evolución de la pobreza; distribución del ingreso o GINI; Índice de Desarrollo Humano elaborado por el Programa de Naciones Unidas para el Desarrollo (PNUD); crecimiento económico; gasto público; y el apoyo de los ciudadanos de estos tres países a la "democracia" a partir de la encuesta anual realizada por la Corporación Latinobarómetro. El período estudiado va de 2000 a 2011. Todo, bajo la óptica de las teorías del desarrollo, en particular, a partir de las aportaciones de Amartya Sen.

Metodológicamente, el artículo realiza un análisis comparativo entre las variables antes señaladas, con el fin de determinar las correlaciones en su evolución y contrastarlos con la teoría. La comparación en este caso entonces, se utiliza como estrategia analítica para poner las hipótesis de estos teóricos a prueba (Pérez, 2008, p. 3). Asimismo, se escogieron los indicadores antes señalados, considero expresan en buena medida elementos que son básicos desde el punto de vista del bienestar social y material -como pobreza, desigualdad, crecimiento, etc.- para compararlos con la adhesión al sistema democrático. Esto con el fin de determinar si el público de los países estudiados hace alguna relación causal entre bienestar social y derechos civiles y políticos, que es lo que plantean los teóricos aquí citados.

Se escogieron estos tres países por sus importantes similitudes presentes y diferencias históricas. Los tres poseen un modelo económico, político y social similar, adoptando reformas coherentes con el mandato del Consenso de Washington, los tres asumieron un modelo de integración que prioriza la lógica Norte-Sur; y los tres hacen frontera con el Océano Pacífico, con las posibilidades que eso conlleva de aprovechar la relación con las pujantes economías asiáticas. De hecho, estos países, junto a México, conforman un grupo informal denominado Alianza del Pacífico, que se explica por estos elementos co- 
munes. Por otro lado, responden a subregiones distintas de Sudamérica, las que tendrían rasgos culturales específicos. Lo crucial es que los tres responden a formas de democracias similares, por lo que se puede evaluar mejor la respuesta de sus respectivas ciudadanías. Asimismo, se escogió el período que va de 2000 a 2011, abarcando momentos de auge y caída importantes en la actividad económica -entre ellos el fuerte crecimiento que va de 2003 a 2007 y el impacto de la crisis internacional en 2009- lo que permitiría observar más claramente la existencia o no, de un correlato con la opinión de la ciudadanía sobre su sistema político.

Desde el punto de vista de su desarrollo histórico-económico, vemos que los tres países corresponden a zonas que Bértola y Ocampo denominan como indoeuropeas, por la fuerte presencia indígena y mestiza en sus respectivos mercados del trabajo (2010, p. 21). Sin embargo, sus estructuras productivas marcan una clara diferencia: si en el caso de Chile su trayectoria está marcada por la minería y una agricultura de clima templado; el caso de Perú está definido por la minería y la agricultura de complejo de hacienda y comunidad indígena; mientras que en el caso de Colombia se trata de complejos de plantaciones de clima tropical, con una importante presencia afro descendiente (Bértola y Ocampo, 2010, p. 26). Precisamente estas tres trayectorias económicas y sociales son las que atraviesan a América Latina y podrían configurar percepciones ciudadanas específicas. Abarcar por tanto una muestra que recoge las estructuras productivas que se replican en toda la región, puede resultar más representativo a la hora de evaluar las respuestas de las distintas ciudadanías ante similares estímulos económico-sociales.

En otro extremo, el concepto democracia puede resultar confuso y no está exento de debate, mas, para los efectos del presente trabajo, se entenderá como un cuerpo de mínimos comunes, que es como se entiende en Latinobarómetro y como lo asumen los teóricos del desarrollo incorporados en este trabajo. Estos mínimos son: sufragio universal, periódico y secreto para elegir las autoridades que deberán administrar el Estado; pluripartidismo, entendido como la posibilidad de que distintas fuerzas y grupos puedan someter al escrutinio ciudadano sus proyectos; libertad de asociación, reunión y circulación; libertad de prensa; y la existencia de un Estado de derecho, es decir, un sistema en el que todos están sometidos a la Ley, elaborada legítimamente por los representantes del pueblo. El presente trabajo no será especialmente escrupuloso en la evaluación del cumplimiento de estos preceptos, al entender que éstos, al historizarse, pierden su pureza. Nos conformaremos con a lo menos la existencia formal -y real en términos relativos- de estos principios. 
En el mismo sentido, en el presente trabajo se aceptan como fuentes validadas de información, los datos que arrojan los indicadores rescatados, como los niveles de pobreza definidos por Comisión Económica para América Latina y el Caribe (CEPAL), el índice de desigualdad GINI, el IDH del Programa de Naciones Unidas para el Desarrollo (PNUD), o los datos de crecimiento y gasto público obtenido de fuentes oficiales. Esto no niega la existencia de debates teóricos y/o metodológicos sobra la validez de dichos indicadores. Al igual que en el caso del concepto de democracia, para efectos del presente trabajo, se entiende que dichos indicadores tal como están constituidos, permiten desarrollar los objetivos del análisis comparativo que se propone esta investigación.

El objetivo del trabajo y la conceptualización de lo que en adelante entenderemos por democracia parece en sí contradictorio. Intentamos identificar una relación entre indicadores socioeconómicos y la valoración de los ciudadanos hacia un modelo de administración de poder estatal vinculado exclusivamente al ámbito de los derechos civiles y políticos. Es aquí donde entran las aportaciones de teóricos como Amartya Sen o las reflexiones del propio José Antonio Ocampo: desarrollo es un fenómeno holístico, multidimensional, que abarca pero supera las variables socioeconómicas, desarrollo entendido como bienestar en el amplio sentido de la palabra, incorporando elementos como la realización personal o libertad. Y más interesante aún, Sen advierte que elementos aparentemente tan abstractos como la libertad, influyen y se potencian con factores como la disminución de la pobreza y el crecimiento económico, ¿por qué? entre otras cosas porque una sociedad de hombres libres sería una sociedad con mayores capacidades para encontrar soluciones a problemas comunes.

Asimismo, en el vínculo entre lo socioeconómico y lo político reside la hipótesis del presente trabajo; y es que la valoración de la población sobre el sistema político que les gobierna es histórica. A más de 20 años del fin de los regímenes militares en la región, la demanda urgente por el respeto a los derechos civiles y políticos, ha dado paso a la creciente demanda por otro tipo de derechos, vinculados a ámbitos asociados al bienestar de la población: suministro de bienes públicos, infraestructuras, equidad social e incluso de riqueza, son las exigencias de hoy. Observar la evaluación del apoyo de la población a la democracia, junto a la evolución de los demás indicadores, podrá darnos luces al respecto. ¿Estarán los latinoamericanos dispuestos a renunciar a derechos civiles y políticos, en función de avances en materia de derechos sociales y culturales? 


\section{El debate sobre desarrollo}

Históricamente, el concepto desarrollo se asoció al aumento de la riqueza de los países, al crecimiento y he ahí quizás el principal aporte de las nuevas teorías sobre el tema: el desarrollo es un fenómeno holístico, que no se entiende sino en función de mejorar la calidad de vida de las personas, o si se prefiere, en lograr que se viva más y mejor. Dentro de este abanico de interrelaciones, destacan no sólo elementos socioeconómicos claves, como la distribución del ingreso o la disminución de la pobreza, sino otros más abstractos y valóricos, como el de la libertad. En este contexto es también que desmienten la premisa ampliamente difundida de que las sociedades deben pagar una suerte de tributo de sufrimiento en función del desarrollo, es decir, hipotecar las posibilidades de tener mayor calidad de vida en el presente en función de una mejor posición futura. Y es que en definitiva, de lo que se trata en el nuevo enfoque, es que la economía debe estar al servicio del bienestar del ser humano y no a la inversa.

En este sentido, el Premio Nobel de Economía y uno de los principales teóricos del desarrollo, Amartya Sen (1998), advierte que desde que se planteara la cuestión del desarrollo tras el fin de la Segunda Guerra Mundial, ésta ha sufrido importantes cambios, "tanto en el ámbito de la experiencia como en el de la teoría del desarrollo económico y social" (p. 75). Dentro del ámbito de la experiencia el autor destaca: el proceso de reconstrucción de Alemania y Japón, que les llevaría al punto de ser economías líderes a nivel mundial; la creación del Estado de bienestar iniciado en Europa y que implicó una alta carga financiera para el Estado; la conversión de Asia Oriental en un foco de rápido crecimiento económico, con un notable desarrollo social y equidad relativa; la crisis y desmoronamiento del bloque soviético; así como la importante expansión económica mostrada por América Latina, sin que se produjera una proporcional reducción de la pobreza; entre otros fenómenos (p. 75). La contrastación que ofrecía la realidad, permitió ir enriqueciendo y modificando las nociones que se tenían sobre desarrollo, dejando atrás viejos tópicos y dando mayor flexibilidad y vuelo a la reflexión teórica.

Frente a esto, el autor concluye que una de las premisas clave que resultó desmontada por la contrastación empírica, fue la aseveración de que:

Las experiencias de desarrollo han demostrado la irracionalidad del intervencionismo estatal en contraste con las virtudes incuestionables de la economía pura de mercado, y de que el requisito indispensable para el desarrollo es el paso de la planificación (económica) al mercado (Sen, 1998, p. 77). 
Al respecto, Sen (1998) plantea que si bien es necesario reconocer las virtudes del mercado, eso "no debe inducirnos a ignorar las posibilidades y los logros ya constatados del Estado o, por el contrario, a considerar al mercado como factor de éxito independiente de toda política gubernamental" (p. 77).

En el mismo sentido, el economista y ex secretario ejecutivo de la CEPAL, José Antonio Ocampo (2001), puntualiza que, "la idea de que la combinación de una economía abierta y una macroeconomía estable (...) puede impulsar, por sí sola, el crecimiento económico, se ha visto frustrada hasta ahora" (p. 6), lo que ha llevado a los defensores de las posiciones económicas más ortodoxas, a señalar que el problema es precisamente que la liberalización ha sido incompleta. Frente a esto, el autor enfatiza:

La etapa de mayor crecimiento de los países en desarrollo es la posguerra y los episodios más prolongados de expansión acelerada (los "milagros" del sudeste asiático y, en los últimos años, de China y la India, así como los períodos de rápido crecimiento de Brasil y México en el pasado) no coinciden con las fases o episodios de mayor liberalización económica (Ocampo, 2001, p. 7).

Por el contrario, Ocampo plantea la necesidad de construir una estrategia de desarrollo productivo, destacando la necesidad de establecer una estrecha colaboración entre el Estado y el sector empresarial. Pero eso no es todo, Ocampo enfatiza la necesidad de incorporar nuevos requerimientos a la hora de generar esa estrategia de desarrollo productivo, que no puede erigirse exclusivamente desde la óptica de maximizar el crecimiento económico. Dentro de esto destaca:

La incorporación efectiva de la agenda de desarrollo sostenible es una demanda adicional sobre las estrategias de desarrollo productivo en la actualidad. De hecho, el alto grado de deterioro ambiental alcanzado por países en etapas intermedias o aun bajas de desarrollo indica que la sostenibilidad no puede ser vista de ninguna manera como un lujo que puede posponerse (Ocampo, 2001, p.10).

De igual manera, esta estrategia debe basarse en la exigencia de enfrentar problemas sociales graves, como la pobreza y la desigualdad. Como sostiene Sen, la preocupación por el crecimiento debe mantenerse, igualmente como prioritaria, ya que provee de mayores fondos públicos para invertir en infraestructura, salud, educación etc. Al respecto, el autor concluye: 
En términos económicos, el progreso social puede concebirse como el producto de tres factores básicos: una política social de largo plazo, destinada a incrementar la equidad y garantizar la inclusión; un crecimiento económico que genere un volumen adecuado de empleos de calidad; y una reducción de la heterogeneidad estructural de los sectores productivos, que reduzca las brechas productivas entre distintas actividades económicas y distintos agentes (Ocampo, 2001, p. 10).

Otro precepto ampliamente extendido que rebate Sen, es el que plantea la regla de que las sociedades deben hacer un 'sacrificio necesario' para alcanzar el desarrollo económico ${ }^{1}$. Esta concepción pone en el centro del desarrollo económico la formación de capital -muchas veces entendido sólo como capital físico- que sólo podría formarse a partir de la acumulación. El problema es que en países pobres, donde la tasa de ahorro es precaria, ¿ de dónde obtener esos excedentes?, pues abaratando el costo de la mano de obra y manteniendo bajos los niveles de vida de la población. Esto permitiría una acumulación acelerada de capital, aumentando las capacidades para un posterior crecimiento económico, superando los problemas de desarrollo. Un planteamiento que, como recuerda el autor, fue característico tras la segunda postguerra y que tuviera como expresión histórica más extrema el proceso de industrialización de la Unión Soviética.

Frente a esto, Sen hace dos críticas íntimamente relacionadas: la deficiencia en el enfoque al no incorporar la inversión en capital humano; y el desinterés hacia el bienestar y la calidad de vida del presente y del futuro inmediato. Es así como para el autor:

El protagonismo asignado a la acumulación de capital no constituía un error en sí mismo, sobre todo cuando empezó a adquirir importancia lo que pronto se denominaría 'capital humano. Todo estudio empírico sobre experiencias exitosas de desarrollo ha demostrado el papel crucial de la acumulación de capital, en su sentido más amplio, en el desarrollo económico, el problema lo constituía entonces, el enfoque que equiparaba la noción de acumulación de capital con la de formación de capital físico (Sen, 1998, p. 80).

1 Sobre los supuestos 'sacrificios necesarios' para alcanzar el desarrollo, desde el plano de resaltar sólo las virtudes del mercado, destacar la premisa de la "Teoría del Derrame”, que planteaba la necesidad de una amplia liberalización de la economía, así como reducción de impuestos y gasto público; para lograr un fortalecimiento de las fuerzas del mercado y con ello, una mayor inversión, crecimiento y empleo, generando un consiguiente bienestar general futuro. Al respecto, el Nobel de Economía, Paul Kurgman, advierte que el período de liberalización que vino a desmontar las políticas sociales y redistributivas del 'New Deal', sólo se tradujo en un aumento de la desigualdad en el ingreso (Krugman, 2007, p. 15). 
Sobre el bienestar, Sen (1998) no sólo apela a la responsabilidad ética, "no puede eludirse el gravísimo problema de la pobreza, aun cuando exista la posibilidad de proporcionar mayores beneficios a una generación futura más prospera” (p. 81), sino también a su potencial económico.

Para el autor, el contraponer el bienestar presente con el futuro, tiene su justificación teórica en el modelo que divide la producción en "consumo" e "inversión", en el que el bienestar estaría enmarcado en el primero, mientras que el crecimiento en el segundo. Frente a esto, Sen señala:

Debemos plantear nuevas fórmulas que tengan en cuenta la correlación entre productividad económica y educación, atención en salud, alimentación y otros aspectos similares. Es indudable que estos factores tienen un efecto inmediato en el bienestar presente. Por consiguiente, para abordar al problema de la 'compensación intertemporal' debemos apartarnos de la dicotomía de las 'decisiones difíciles', en la que se basó la literatura sobre el crecimiento óptimo (1998, p. 82).

Pero no es sólo un problema económico, la inversión social también impacta positivamente en otros campos clave:

Algunos de los efectos del consumo social, incluidos la educación y la atención en salud van más allá de la productividad económica y del bienestar inmediato. Por ejemplo, la educación y el empleo remunerado de las mujeres pueden incidir en la reducción de las desigualdades de género, elemento central del subdesarrollo en muchos lugares del mundo (Sen, 1998, p. 82).

Otra modalidad de la teoría que justifica los sacrificios presentes en pos de beneficios futuros, plantea que en las primeras etapas del desarrollo es necesario renunciar al ejercicio pleno de los derechos civiles y políticos. Este enfoque se erige desde la experiencia de países asiáticos de rápido crecimiento, como China, Taiwán, o Corea del Sur, que mantienen o mantuvieron regímenes que restringían ese tipo de derechos. Sen refuta esos planteamientos al señalar que:

Las condiciones particulares que contribuyeron al éxito de las economías de Asia Oriental incluían la competencia sin restricciones, la participación en los mercados internacionales, altos índices de alfabetización y educación, una reforma agraria efectiva e incentivos a las inversiones, las exportaciones y la industrialización. Nada nos induce a pensar que estas políticas sociales son inconsistentes con la democracia auténtica, o 
que sólo pueden llevarse a cabo en regímenes autoritarios. (...) Debernos considerar los vínculos entre los derechos políticos y civiles y las prevención de desastres sociales mayores. Los derechos políticos y civiles tendrían un efecto incentivador a la hora de asociar un gobierno eficiente con el ejercicio de esos derechos (1998, p. 85).

Y concluye: "Se debe señalar que, en la terrible historia del hambre en el mundo, ningún país dotado de un gobierno democrático y una prensa más o menos libre ha sufrido hambrunas de grandes proporciones" (Sen, 1998, p. 86).

Este es uno de los aspectos centrales de las aportaciones de Sen a las teorías sobre el desarrollo: el problema de la libertad. Poner en el centro del desarrollo a las libertades humanas supera la visión tradicional de identificarlo con el crecimiento económico. Para el autor:

El incremento de los ingresos personales, la industrialización, el avance tecnológico o la modernización social. [Estos elementos] pueden, desde luego, representar un medio muy importante para ampliar las libertades de las que disfrutan los miembros de una sociedad, sin embargo, esas libertades dependen también de otros factores, como los planes sociales y económicos (programas de educación y el cuidado de la salud) y los derechos civiles y políticos (libertad para participar en el debate y el escrutinio públicos) (2000, p. 15).

Asimismo, enfatiza que la libertad no puede valorarse sólo en función de su aporte al crecimiento económico, sino su capacidad de mejorar la calidad de vida de las personas, "los ciudadanos de Namibia, Sudáfrica o Brasil pueden ser mucho más ricos en términos de PNB per cápita que los de Sri Lanka o China, pero los últimos tienen expectativas de vida sustancialmente más altas que los primeros" (Sen, 2000, p. 16).

El enfoque del desarrollo como libertad plantea una serie de interacciones positivas en el resto de las relaciones sociales. De hecho, para Sen (2000), "La ausencia de libertad económica puede generar ausencia de libertad social, de igual forma que la ausencia de libertad social o política puede fomentar la ausencia de libertad económica" (p. 17). En términos más específicos, señala que las llamadas libertades instrumentales: 1) libertades políticas, 2) facilidades económicas, 3) oportunidades sociales, 4) garantías de transparencia, y 5) redes de seguridad- bajo el prisma del desarrollo como libertad; se enlazan y potencian en función del mejoramiento de la libertad humana en general. En este sentido, Sen enfatiza que las libertades: 
No son solamente los fines primarios del desarrollo; son también sus principales medios. (...) Las libertades políticas (en forma de libertad de expresión y elecciones) ayudan a promover la seguridad económica; las oportunidades sociales (en forma de educación y servicios de salud) facilitan la participación económica; los medios económicos (en forma de oportunidades para participar en el comercio y la producción) pueden ayudar a generar abundancia personal así como recursos públicos para servicios sociales (2000, p. 20).

Finalmente, destacar otro aspecto crucial de los planteamientos teóricos de Sen (1997): la necesidad de expandir la 'capacidad humana'. Ante esto, el autor separa dos conceptos, que aunque relacionados, son diferentes: la acumulación de capital humano y el de la expansión de la capacidad humana. El primero tiene un carácter eminentemente económico, en el que mediante la adquisición de habilidades y conocimientos, el actor en cuestión aumenta sus posibilidades productivas; el segundo en tanto, se centra en su "habilidad para llevar el tipo de vida que consideran valiosa e incrementar sus posibilidades reales de elección." (p. 1).En este sentido, Sen lo ejemplifica con el caso de la educación, es decir, una persona formada puede agregar valor a su producción, habiendo una mejora entonces en capital humano; pero por otro lado, la educación también ofrece otros beneficios, como poder leer, escribir, mejorar su capacidad de argumentar, tener mayor información a la hora de elegir, etc., que implica una mejora en las capacidades humanas.

De modo que los beneficios de la educación son mayores que su función de capital humano en la producción de bienes. La perspectiva más amplia de capacidad humana puede abarcar -y valorar- estas funciones adicionales. Las dos perspectivas están, entonces, íntimamente relacionadas aunque sean distintas (Sen, 1997, p. 2).

En síntesis, el centro del desafío intelectual que nos impone Sen y otros teóricos del desarrollo, es entenderlo como un fenómeno integral, que incorpora pero supera las variables económicas. Elementos como libertad, realización personal y bienestar no sólo están relacionados, sino que impactan a las variables económicas. Pero, lo más importante, permiten avanzar hacia lo que debería estar en el centro del quehacer humano: su felicidad. 


\section{Variables sociales, económicas y apoyo a la democracia}

América Latina en la última década ha mostrado, en términos generales, un sólido desempeño en los principales indicadores sociales y económicos. En este aspecto pueden identificarse tres grandes períodos: el primero que va de 2003 a 2007, denominado quinquenio virtuoso por las altas y sostenidas tasas de crecimiento, así como por la constante en la disminución de la pobreza y en menor medida, la desigualdad; un segundo período marcado por la crisis global de 2008-2009, en donde cae el crecimiento y hay un ligero deterioro en términos de pobreza; y el tercer período, el de la recuperación. Cabe destacar el impacto relativamente menor en América Latina, de la crisis originada en Estados Unidos, lo que se explica en primer lugar por el creciente espacio que ocupa la demanda china de materias primas; $y$ en segundo por una eficaz política fiscal contracíclica. Todo, además, en ambientes institucionales democráticos. Sin embargo, a primera vista no pareciera que los latinoamericanos reconozcan estos períodos de bonanza o que los asocien con el modelo político, ya que en promedio casi la mitad de los ciudadanos de la región no apoya el sistema democrático.

Específicamente en cuanto al apoyo manifiesto de los latinoamericanos a la democracia, éste ha mostrado una trayectoria de subidas y bajadas anuales que en algunos casos alcanzan oscilaciones de 10 puntos porcentuales, quedando la media en torno al \% de respaldo (57\% para ser precisos), entre 1995 y 2011 (Corporación Latinobarómetro). En términos de crecimiento, el período que va de 2003 a 2007 está marcado por una expansión productiva y una estabilidad macroeconómica que no se veía en décadas, lo que a su vez se vio complementado por una mejora en los principales indicadores sociales. La crisis de 2008 impacta a la región, pero de forma mucho más moderada que la crisis asiática. El Producto Interno Bruto (PIB) pasó de un crecimiento del 5,8\% en 2007 y un $4 \%$ en 2008; a una caída del $-1,2 \%$ en 2009 , pero la recuperación se inició pronto y ya en el segundo semestre de 2009 comenzó a retomarse la senda del crecimiento, alcanzando en 2010 un crecimiento del 6,2\%. La crisis no mostró impacto en los índices de pobreza, que continuaron su tendencia a la baja mostrada durante el quinquenio virtuoso, con un 33,5\% en 2008; un 32,9\% en 2009; y un 31\% en 2010 (Cepalstat). La situación de desigualdad sigue una evolución similar. Esto puede asociarse a políticas sociales más eficaces, que mostraron un ciclo de disminución de la pobreza resistente a la baja en el crecimiento.

El que la región enfrentara de buena forma los avatares de la crisis financiera, se explica por una combinación de factores externos e internos. En el primer caso, el aumento de la demanda asiática de materias primas amortiguó la caída de la demanda 
norteamericana y europea, lo que se evidencia particularmente en los países productores de minerales, que concentran, junto al petróleo, las exportaciones hacia el otro extremo del Pacífico, en los países analizados. En el plano interno, cabe destacar dos políticas que permitieron contrarrestar los efectos de la crisis: en primer lugar una política de gasto fiscal contracíclica que fue efectiva en generar demanda interna en momentos que la externa se deterioraba; mientras que en segundo, una inflación controlada evitó que decayera el poder adquisitivo de los asalariados, un aspecto crucial si consideramos que son los ingresos laborales, más que las transferencias públicas, las que explican la disminución en los índices de pobreza en los países referidos.

La situación específica de los tres países que analizamos en el presente trabajo se explicita en las siguientes tablas:

Tabla 1

Chile: Relación entre indicadores sociales y económicos, con el apoyo ciudadano a la democracia

\begin{tabular}{|c|c|c|c|c|c|c|c|c|c|c|c|c|}
\hline Indicadores & 2000 & 2001 & 2002 & 2003 & 2004 & 2005 & 2006 & 2007 & 2008 & 2009 & 2010 & 2011 \\
\hline $\begin{array}{l}\text { Crecimiento } \\
\text { económico }\end{array}$ & 4,5 & 3,4 & 2,2 & 3,9 & 6 & 5,6 & 4,6 & 4,6 & 3,7 & $-1,7$ & 5,2 & 6,2 \\
\hline $\begin{array}{l}\text { Gasto Fiscal } \\
\text { Gob. Central } \\
\text { (\%PIB) }\end{array}$ & 21,8 & 22,1 & 22,3 & 21,1 & 19,9 & 19,3 & 18,1 & 18,7 & 21,2 & 24,8 & 23,4 & $\ldots$ \\
\hline $\begin{array}{l}\text { Índice } \\
\text { desigualdad } \\
\text { (GINI) }\end{array}$ & 0.564 & $\ldots$ & $\ldots$ & 0.552 & $\ldots$ & $\ldots$ & 0.522 & $\ldots$ & $\ldots$ & 0.524 & $\ldots$ & $\ldots$ \\
\hline $\begin{array}{l}\text { Variación } \\
\text { niveles de } \\
\text { pobreza (\%) }\end{array}$ & 20,2 & $\ldots$ & $\ldots$ & 18,7 & $\ldots$ & $\ldots$ & 13,7 & $\ldots$ & $\ldots$ & 11,7 & $\ldots$ & $\ldots$ \\
\hline $\begin{array}{l}\text { Índice } \\
\text { Desarrollo } \\
\text { Humano } \\
\text { (IDH) }\end{array}$ & 0.749 & $\ldots$ & $\ldots$ & $\ldots$ & $\ldots$ & 0.779 & $\ldots$ & $\ldots$ & $\ldots$ & 0.798 & 0.802 & 0.805 \\
\hline $\begin{array}{l}\text { Encuesta } \\
\text { Apoyo a la } \\
\text { Democracia }\end{array}$ & 57 & 45 & 50 & 51 & 57 & 59 & 56 & 46 & 51 & 59 & 63 & 61 \\
\hline
\end{tabular}

Fuente: Elaboración propia (CEPAL 2011; Cepalstat; Corporación Latinobarómetro 2000-2011, PNUD 2011). 
En la tabla 1, podemos observar el caso de Chile, donde las variaciones en la actividad económica dan cuenta en forma muy marcada de los ciclos mundiales, con un crecimiento sostenido entre 2000 y 2002 aunque modesto, para entrar en el quinquenio virtuoso de 2003 a 2007, marcado por el auge en la demanda de materias primas, en particular minerales, por parte del gigante chino. Luego se cae en la crisis financiera iniciada en 2007 pero desatada en 2008. Para después, iniciar la recuperación en 2010. El gasto fiscal muestra un comportamiento contracíclico. De 2000 a 2003 en que el crecimiento se muestra más débil, el gasto se mantiene siempre por sobre el 21\% del PIB. De 2004 a 2007, en que la actividad económica aparece reforzada, el gasto público baja del $20 \%$ del PIB. Pero en el período de la crisis, ya desatada en 2008, el gasto supera el $21 \%$ y en 2009, con un proceso recesivo en marcha, se empina a casi el $25 \%$ del producto, para luego descender ligeramente en 2010, una vez que la economía muestra su recuperación. Esta política sin duda logró paliar los nocivos efectos de la crisis financiera y dar un impulso a la actividad por la vía de estimular la demanda interna.

Los índices sociales que podríamos identificar más directamente con la calidad de vida de la población, parecen auspiciosos, es decir, en general estos indicadores mejoran y aunque la crisis de 2008 parece haber tenido un impacto, éste resultó ser limitado. Entre 2000 y 2007 el indicador de distribución del ingreso (GINI) mejora, y aunque en el resultado de 2009 hay un leve retroceso con respecto a la medición anterior de 2006, sigue siendo mejor que las mediciones de 2003 y 2000. En cuando a porcentaje de pobreza con respecto al total de la población, ésta disminuye en forma constante a pesar de la crisis, pasando de poco más del 20\% en 2000, a menos del 12\% en 2009. Finalmente, el Índice de Desarrollo Humano (IDH) muestra también una mejora sostenida durante todo el período analizado, siendo Chile, junto a Argentina, los únicos países latinoamericanos en estar en el grupo de países con un IDH 'muy alto'.

En este contexto, el nivel de apoyo ciudadano a la democracia es el indicador que muestra mayores variaciones, junto al crecimiento económico, pero sus variaciones no parecen vinculadas. Es decir, en algunos años aumenta el apoyo ciudadano junto con un repunte del crecimiento, y también hay años en que la caída en la actividad coincide con la baja en el apoyo democrático, pero otros en que el registro es inverso. Un ejemplo ilustrativo es que en 2006-2007 se registró el mismo índice de crecimiento y casi igual porcentaje de gasto público, pero el apoyo a la democracia varió en 10 puntos porcentuales. Por otro lado, las tendencias al alza de los indicadores sociales, vistos en una relación anualizada, tampoco parecen coincidir con las variaciones en el resultado de esta encuesta de opinión. 
Tabla 2

Perú: Relación entre indicadores sociales y económicos, con el apoyo ciudadano a la democracia

\begin{tabular}{|c|c|c|c|c|c|c|c|c|c|c|c|c|}
\hline Indicadores & 2000 & 2001 & 2002 & 2003 & 2004 & 2005 & 2006 & 2007 & 2008 & 2009 & 2010 & 2011 \\
\hline $\begin{array}{l}\text { Crecimiento } \\
\text { económico }\end{array}$ & 2,7 & 0,6 & 2,2 & 4,2 & 7,5 & 6,9 & 7,7 & 8,9 & 9,8 & 0,9 & 8,8 & 6,9 \\
\hline $\begin{array}{l}\text { Gasto Fiscal } \\
\text { Gob. Central } \\
\text { (\%PIB) }\end{array}$ & 17,96 & 17,25 & 16,63 & 16,70 & 16,20 & 16,53 & 16,10 & 16,36 & 15,9 & 17,3 & 17 & $\ldots$ \\
\hline $\begin{array}{l}\text { Índice } \\
\text { desigualdad } \\
\text { (GINI) }\end{array}$ & $\ldots$ & 0.525 & $\ldots$ & 0.530 & $\ldots$ & $\ldots$ & $\ldots$ & 0.500 & 0.476 & 0.469 & 0.458 & $\ldots$ \\
\hline $\begin{array}{l}\text { Variación } \\
\text { niveles de } \\
\text { pobreza (\%) }\end{array}$ & $\ldots$ & 54,8 & $\ldots$ & 54,7 & 48,6 & 48,7 & 44,5 & 39,3 & 36,2 & 34,7 & $\ldots$ & $\ldots$ \\
\hline $\begin{array}{l}\text { Índice } \\
\text { Desarrollo } \\
\text { Humano (IDH) }\end{array}$ & 0.674 & $\ldots$ & $\ldots$ & $\ldots$ & 0.69 & $\cdots$ & $\ldots$ & $\ldots$ & $\ldots$ & 0.71 & 0.72 & 0.73 \\
\hline $\begin{array}{l}\text { Encuesta Apoyo } \\
\text { a la Democracia }\end{array}$ & 64 & 62 & 57 & 52 & 45 & 40 & 55 & 47 & 45 & 52 & 61 & 59 \\
\hline
\end{tabular}

Fuente: Elaboración propia (CEPAL 2011; Cepalstat; Corporación Latinobarómetro 2000-2011; PNUD, IDH 2007-2011).

En la tabla 2, podemos analizar las cifras de Perú. Este país, en cuanto a sus índices de crecimiento, se acopla a la tendencia general latinoamericana, aunque con alzas y caídas en la actividad más pronunciados. El periodo 2000-2002 hay un crecimiento bajo, para luego pasar a un largo período de alto crecimiento que se inicia en 2003 y que llega a 2008 con un crecimiento de casi el 10\%. Luego está la fuerte caída de 2009 como expresión de la crisis mundial, pero se observa una rápida recuperación a partir del año siguiente. En el caso de la política fiscal, aunque ésta muestra una tendencia contracíclica, el gasto es poco agresivo, las variaciones van entre uno y uno y medio punto porcentuales, nunca alcanzando el 18\% del PIB. Parece ser que fue la demanda externa lo que explicó en mayor medida la recuperación tras la crisis, más que el incentivo de la demanda doméstica.

Frente a los índices sociales, Perú muestra una tendencia de mejora bastante estable. Salvo por el retroceso en la distribución del ingreso que se observa en 2003, la ten- 
dencia es de mejora permanente tanto en GINI, como en la disminución de la pobreza, así como en el Índice de Desarrollo Humano (IDH). Sin embargo, cabe señalar que si bien entre 2001 y 2009 la pobreza disminuyó en 20 puntos porcentuales, aún un tercio de la población vive en esta situación. Señalar también que en cuanto a IDH, Perú se mantiene en la zona de países con un nivel 'alto'. En cuanto al nivel de apoyo ciudadano a la democracia, este fluctúa entre el $40 \%$ y el $60 \%$, pero esas fluctuaciones, si se mira en forma anualizada, no parecen coincidir con los resultados de los demás indicadores.

TABLA 3

Colombia: Relación de indicadores sociales y económicos, con apoyo ciudadano a la democracia

\begin{tabular}{|c|c|c|c|c|c|c|c|c|c|c|c|c|}
\hline Indicadores & 2000 & 2001 & 2002 & 2003 & 2004 & 2005 & 2006 & 2007 & 2008 & 2009 & 2010 & 2011 \\
\hline $\begin{array}{l}\text { Crecimiento } \\
\text { económico }\end{array}$ & 2,9 & 1,5 & 1,9 & 3,9 & 4,9 & 5,2 & 6,7 & 6,9 & 3,5 & 1,5 & 4,3 & 4,6 \\
\hline $\begin{array}{l}\text { Gasto } \\
\text { Fiscal Gob. } \\
\text { Central } \\
\text { (\%PIB) }\end{array}$ & 15,57 & 17,02 & 17,44 & 16,88 & 17,44 & 17,46 & 18,08 & 17,70 & 17,90 & 19,25 & 17,5 & $\ldots$ \\
\hline $\begin{array}{l}\text { Índice } \\
\text { desigualdad } \\
\text { (GINI) }\end{array}$ & $\ldots$ & $\ldots$ & 0.594 & 0.573 & 0.579 & 0.580 & $\ldots$ & ... & 0.589 & 0.578 & 0.578 & $\ldots$ \\
\hline $\begin{array}{l}\text { Variación } \\
\text { niveles de } \\
\text { pobreza (\%) }\end{array}$ & $\ldots$ & $\ldots$ & 54,1 & $\ldots$ & 51,1 & 50,6 & $\ldots$ & $\ldots$ & 46,1 & 45,7 & $\ldots$ & $\ldots$ \\
\hline $\begin{array}{l}\text { Índice } \\
\text { Desarrollo } \\
\text { Humano } \\
\text { (IDH) }\end{array}$ & 0.652 & $\cdots$ & $\ldots$ & $\ldots$ & $\cdots$ & 0.68 & $\ldots$ & $\ldots$ & $\ldots$ & 0.7 & 0.71 & 0.71 \\
\hline $\begin{array}{l}\text { Encuesta } \\
\text { Apoyo a la } \\
\text { Democracia }\end{array}$ & 50 & 36 & 39 & 46 & 46 & 46 & 53 & 47 & 62 & 49 & 60 & 55 \\
\hline
\end{tabular}

Fuente: Elaboración propia (CEPAL 2011; Cepalstat; Corporación Latinobarómetro 2000-2011; PNUD 2011.

Finalmente, en la tabla 3, se da cuenta de las estadísticas de Colombia. El país muestra el mismo patrón de auge y caída en el crecimiento, con una muy débil actividad de 2000 a 2002, y un período de mayor crecimiento entre 2003 y 2007, siendo 2009 el peor año como consecuencia de la crisis internacional. Cabe mencionar que en cuanto 
a crecimiento, Colombia muestra en general un nivel más bajo que Perú y Chile. Esto puede explicarse ante el hecho de que la demanda asiática tiende a concentrarse en recursos minerales, frente a otros, lo que puede haber resultado más beneficioso para Lima y Santiago como potencias mineras.

En cuanto a gasto público, éste no parece seguir una clara tendencia contracíclica, siendo procíclica en algunos años. Llama la atención que en 2006 y 2007, años en el que el país muestra el mayor crecimiento de la serie $(6,7 \%$ y $6,9 \%$ respectivamente) también muestre los mayores niveles de gasto público (18,08\% y 17,70\%). En 2009, cuando el país vivía lo peor de la crisis, se ve un gasto extraordinario superior al 19\%, el mayor del período analizado. En general el gasto público se mantiene a niveles muy similares a Perú, por debajo del 18\% del producto. Quizás una explicación para lo aparentemente 'errático' de la política de gasto -a veces contra y otras pro ciclo económico- se encuentre en el gasto en seguridad, que obedece a otros criterios, vinculados al conflicto interno que vive el país.

En cuanto a las variables sociales, su evolución no parece seguir la curva de mejoría que en general muestra América Latina. Sólo en el plano de la pobreza se exhibe una mejoría permanente a lo largo de los años, aunque los niveles siguen siendo muy altos, superando al 45\% de la población en su mejor resultado. En cuando al GINI, si bien el índice de 2010 es mejor al de 2002 (el primer y último registro estudiado), las mediciones intermedias muestran avances y retrocesos a lo largo de los años, siguiendo una línea más bien de estancamiento. Lo mismo ocurre con el IDH, tiende a mejorar, aunque también muestra caídas, el país está en el grupo de quienes tienen un IDH 'alto'. En cuanto a los niveles de apoyo a la democracia, visto en forma anualizada, no parece que las variaciones en este índice coincidan con la de los demás.

Por su parte, la relación entre los tres países, a partir de cada uno de los índices estudiados, se muestra en las siguientes figuras ${ }^{2}$ :

2 Los gráficos se realizaron introduciendo los datos de cada indicador, disponibles en las tablas que aparecen en este mismo artículo, a las plantillas de gráficos del programa Excel. 


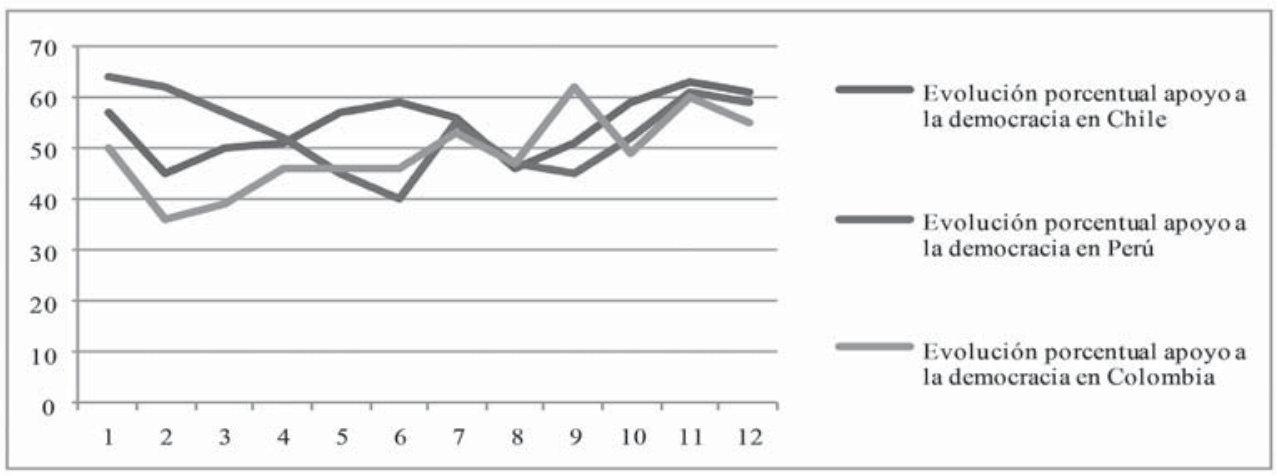

Figura 1. Variación porcentual de variable "Apoyo a la democracia”, en los tres países analizados, período anualizado 2000-2011. Fuente: Elaboración propia (Latinobarómetro 2000-2011).

En la figura 1 se destacan dos importantes elementos de los tres países: las fuertes fluctuaciones en cuando a apoyo a la democracia, y que éste en el mejor de los casos se empina levemente sobre el 60\%, todo a lo largo de los 12 años estudiados. Frente a las diferencias, se observa un Chile más estable en cuanto a la evolución de su apoyo a la democracia, destacando la fuerte caída en torno a 2003 y 2009, coincidiendo con los impactos negativos de las crisis económicas internacionales, para volver a tomar la senda de crecimiento hasta instalarse en la cabeza de la lista en 2010, aunque con una leve baja respecto del año anterior. En el caso de Colombia y Perú las fluctuaciones son mayores, aunque al igual que Chile, culminan con una leve tendencia a la baja tras el alza de 2010.

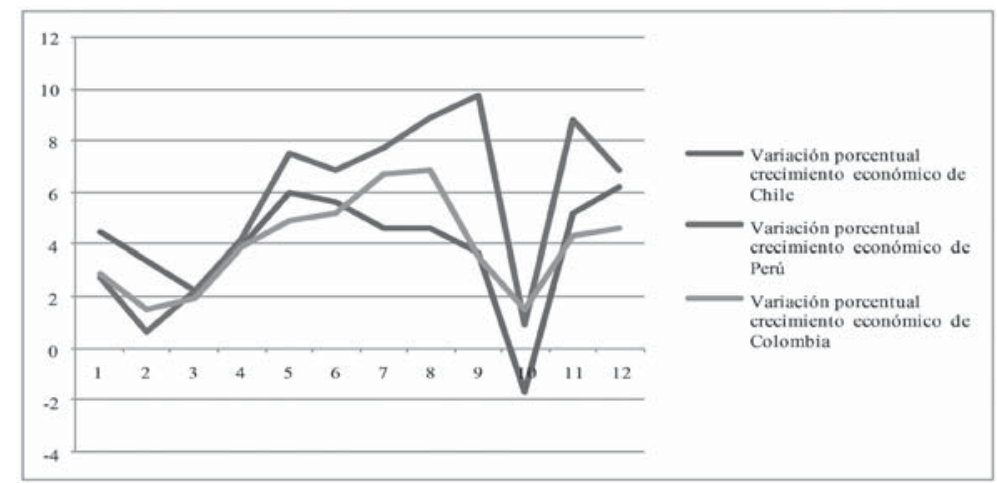

Figura 2 Variación porcentual de variable “Crecimiento Económico”, en los tres países analizados, para período anualizado 2000-2011. Fuente: Elaboración propia (Cepalstat). 
En la figura 2 se evidencia la evolución del crecimiento, donde los tres países siguen una senda similar: débil crecimiento entre 2000 y 2002, para iniciar una importante alza en el período 2003 y 2007, con una marcada caída en 2008 por la crisis internacional. Llama la atención que Chile y Perú son los más afectados, en particular el primero, lo que es atribuible a la caída en las exportaciones de minerales y otras materias primas, a Europa y Estados Unidos. Finalmente destacar la recuperación que prontamente muestra la actividad económica, la que luego se ralentiza al final del período estudiado, con especial impacto en Perú.

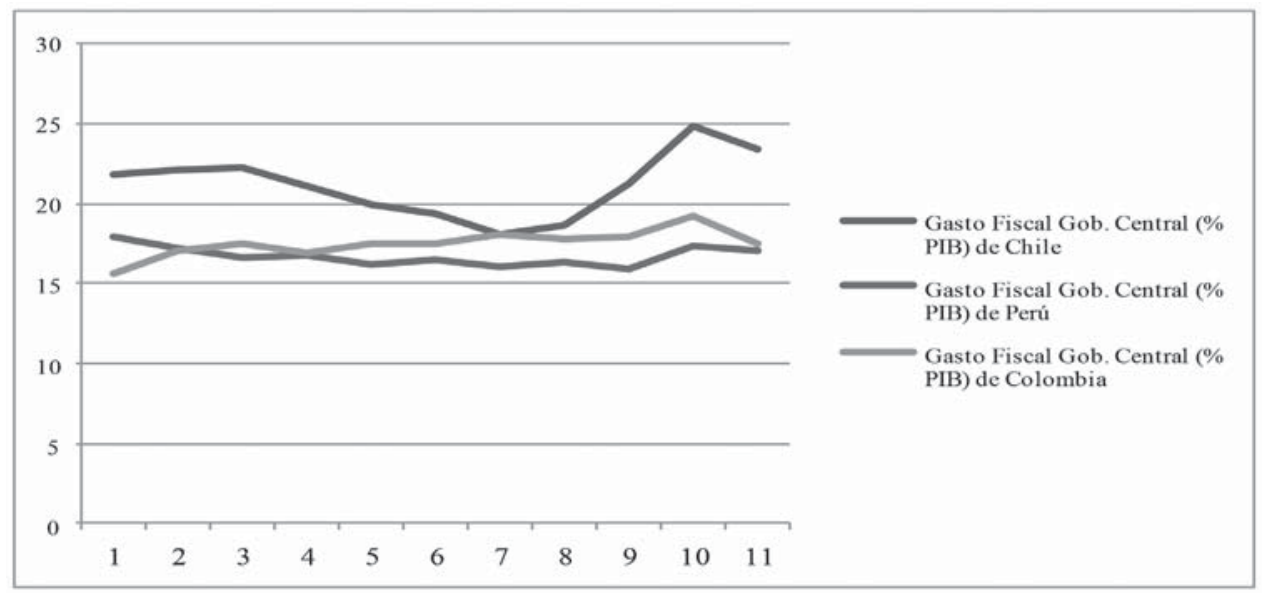

Figura 3. Variación porcentual de variable "Gasto Fiscal del Gobierno Central”, en los tres países analizados, para período anualizado 2000-2010. Fuente: Elaboración propia (Cepalstat).

En la figura 3, se muestra que frente al uso del gasto público como instrumento contracíclico, destaca el caso chileno, en donde claramente se ve las variaciones del gasto que aumenta en los períodos recesivos para contenerse en los de auge. Frente a esto, la política fiscal de los vecinos es menos activa como instrumento de política pública, manteniéndose más estable en el tiempo, para casi converger al final del período estudiado. 


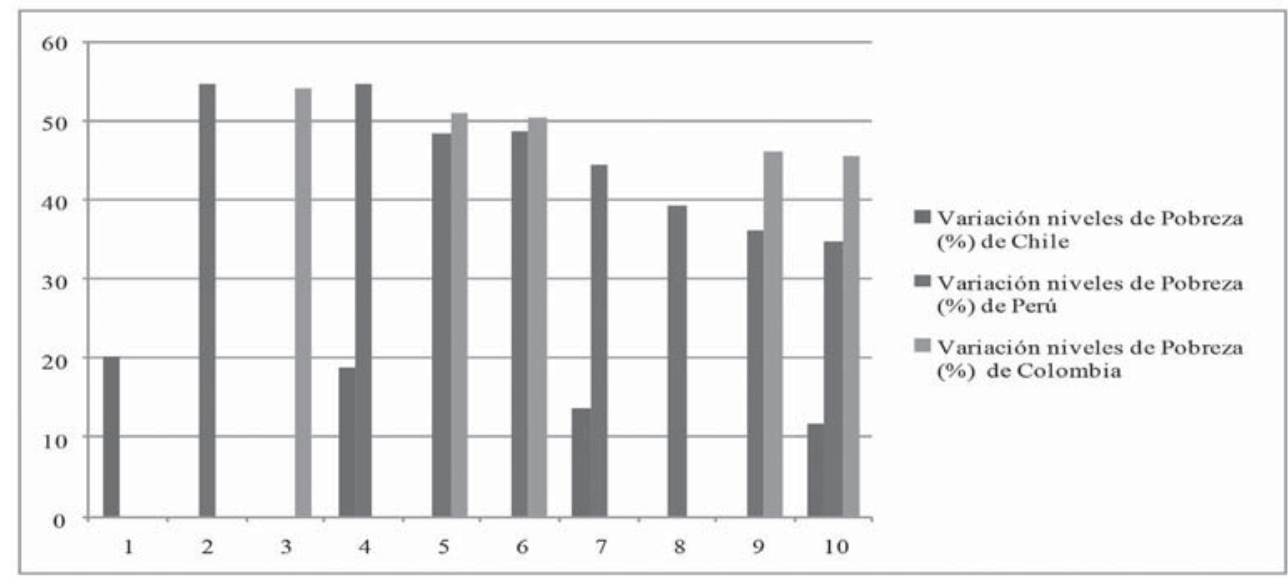

Figura 4. Variación porcentual de variable "Niveles de Pobreza", en los tres países analizados, a partir de mediciones disponibles entre 2000 y 2009. Fuente: Elaboración propia (Cepalstat).

En la figura 4 puede verse que si bien en la comparación de los índices de pobreza nos encontramos con que no existen datos para todos los años estudiados, la información existente permite de todas formas establecer las principales relaciones. Chile ciertamente destaca como el país con menores niveles de pobreza, mostrando a su vez una clara tendencia a la disminución. Colombia y Perú muestran niveles de pobreza considerablemente mayores, aunque también dan cuenta de una tendencia a la baja, proceso en el que Perú se muestra más exitoso: al principio de la gráfica sus índices de pobreza están virtualmente al nivel de Colombia, mientras que al final la diferencia es considerable. 


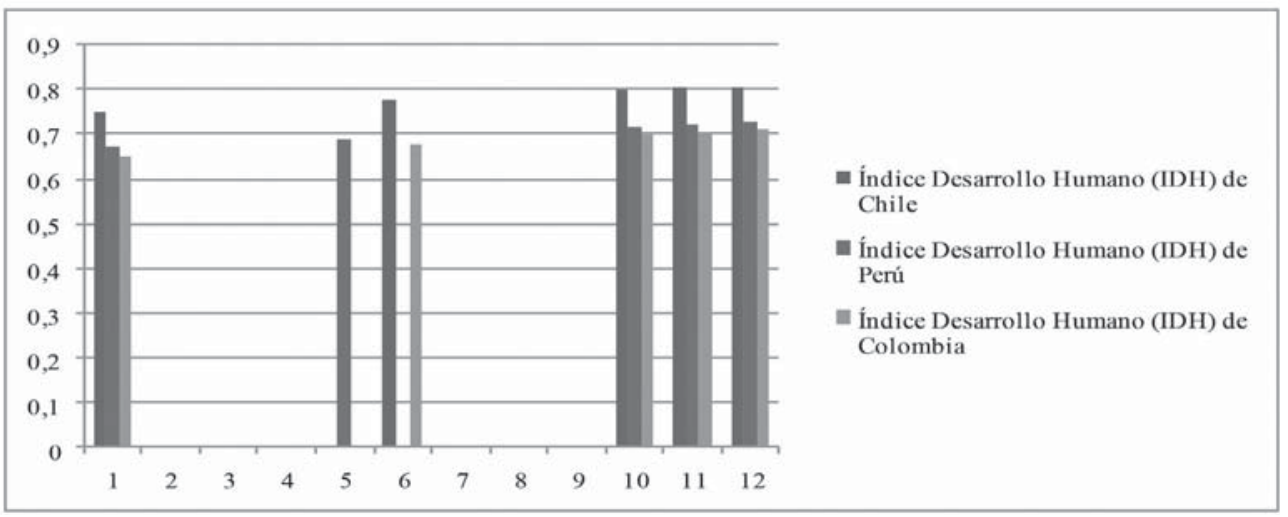

Figura 5. Evolución de variable "Îndice de Desarrollo Humano (IDH)", en los tres países analizados, a partir de mediciones disponibles para período 2000-2011. Fuente: Elaboración propia (Cepalstat)

En la figura 5 puede verse que en cuanto al IDH, Chile supera a los otros dos países analizados en toda la gráfica, mostrando además una clara tendencia ascendente. Perú levemente superior a Colombia y ambos con una tendencia al alza.

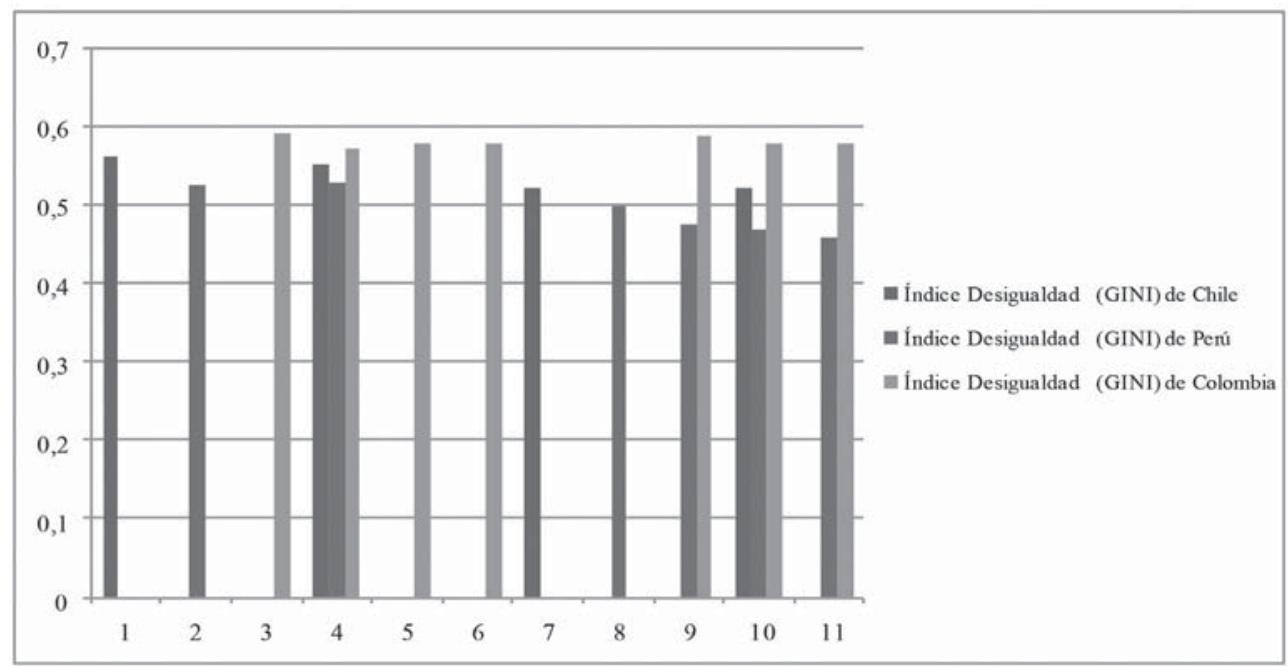

Figura 6. Evolución de variable "Índice de Desigualdad (GINI)", en los tres países analizados, a partir de mediciones disponibles para período 2000-2010. Fuente: Elaboración propia (Cepalstat). 
En la figura 6, se observa que en el plano de la desigualdad, Colombia es el que peores resultados muestra, además de una trayectoria errática, sin claros signos de mejoría. Le sigue Chile, el que tampoco muestra una tendencia clara para la disminución de la desigualdad. En este ámbito es Perú el que ostenta mejores registros, ya que no sólo exhibe menores niveles de desigualdad, sino que es el único que evidencia una trayectoria de mejoría.

\section{Conclusiones}

Los teóricos del desarrollo parecen haber construido un planteamiento sólido en cuanto a vincular elementos económicos, sociales y políticos, como factores que pueden retroalimentarse para avanzar en la calidad de vida y el bienestar de las personas. Planteamiento respaldado además por abundantes referencias empíricas. ¿Son capaces los latinoamericanos y especialmente los chilenos, peruanos y colombianos, de ver esa relación? A primera vista, si los datos se comparan en relación a los años respectivos, la relación no logra verse, el apoyo a la democracia parece moverse en forma aleatoria, no siguiendo el patrón de los índices sociales o económicos. Sin embargo, si se hace un promedio de los resultados de manera interanual, sí se logra ver la relación. Los países con menores índices de pobreza y más alto desarrollo humano promedio durante los 12 años estudiados, son los que muestran un mayor apoyo a la democracia.

Chile es el país que muestra un mayor apoyo ciudadano a la democracia, con un promedio entre 2000 y 2011, del 55\%. Perú le sigue con un promedio del 53\% para el mismo período, mientras que Colombia ocupa el tercer lugar con el $49 \%$. La misma relación se establece si se compara con los índices de pobreza: Chile es el país con menor proporción de pobres en relación al total de la población, con un $11,7 \%$ en 2009 , con una inalterable tendencia a la disminución, el país en este índice ha mostrado mejor desempeño que los demás en todos los años analizados; Perú llega al 34,7\% en 2009 y muestra el segundo mejor desempeño general; mientras que por último está Colombia, con un porcentaje de pobreza del 45,7\%. En cuando al Índice de Desarrollo Humano, se sigue la misma relación, Chile es el que ostenta primer lugar, seguido por Perú y luego Colombia. En ningún otro índice se observa esta convergencia: en nivel de desigualdad, es Perú el que registra los mejores resultados, seguido por Chile y por último Colombia. En crecimiento, Perú también muestra el promedio más alto, con un 5,6\% para el período analizado; luego viene Chile con un $4 \%$, seguido de cerca por Colombia, con un 3,9\%. Finalmente en gasto público, si bien, coincidentemente con el nivel de apoyo a la demo- 
cracia, Chile tiene el nivel más alto, con un promedio para el período del 19,4\% del PIB, quien le sigue es Colombia y no Perú, con un promedio del 17\%; mientras que este último queda con el $16,7 \%$.

A la pregunta inicial, si los latinoamericanos estarían dispuestos a renunciar a la democracia en función de potenciales beneficios en materia socioeconómica, la respuesta parece ser sí y no, es decir, cuando el sistema político es capaz de enfrentar los problemas sociales más graves, como es la pobreza, los ciudadanos están más dispuestos a apoyar su permanencia, que cuando no es capaz de resolverlos.

El presente trabajo además, tiende a desmontar un tópico extendido en cuanto a que la desigualdad en América Latina, la segunda región con la peor distribución del ingreso del mundo, sería una de las causas del bajo nivel relativo de apoyo de la población a la democracia. Sin embargo, en la presente investigación no fue posible establecer una relación causal entre uno y otro fenómeno. A la luz de los datos expuestos, a los latinoamericanos no les importa tanto la desigualdad a la hora de respaldar el sistema político, en la medida que se vayan disminuyendo los índices de pobreza. El nivel de pobreza además, en buena medida determina el nivel de IDH, dado que impacta en variables clave del instrumento del PNUD, como la esperanza de vida y la tasa de alfabetización.

A modo de conclusión, de la investigación se desprende que es el nivel de pobreza el factor clave, dentro de las variables analizadas, que se interrelaciona con las variaciones en el nivel de apoyo ciudadano a la democracia, en los países analizados. Menores índices de pobreza coinciden con mayores niveles de apoyo ciudadano a la democracia. El resultado se presenta coherente entonces con los planteamientos de los teóricos del desarrollo analizados, en cuanto a que la libertad política está dialécticamente vinculada con el desarrollo económico. Como ejemplo y a la luz del marco teórico analizado, no resulta casual entonces, que precisamente el país que presenta una peor situación en cuanto a respeto de los derechos humanos, sea el que muestre los mayores índices de pobreza y los de menor apoyo ciudadano a la democracia. 


\section{Referencias}

Bértola, L. y Ocampo, J. A. (2010). Desarrollo, vaivenes y desigualdad: una historia económica de América Latina desde la independencia. Madrid, España: Secretaría Regional Iberoamericana. Recuperado de http://segib.org/publicaciones/files/2010/12/HistoriaEconomica-AL-ESP.pdf

CEPALSTAT Bases de datos y publicaciones estadísticas, Comisión Económica de Naciones Unidas para América Latina y el Caribe (CEPAL). Recuperado de http://estadisticas. cepal.org/cepalstat/WEB_CEPALSTAT/Portada.asp

Comisión Económica para América Latina y el Caribe CEPAL (2011). Panorama social de América Latina 2011. Santiago, Chile: Comisión Económica de Naciones Unidas para América Latina y el Caribe (CEPAL).

Corporación Latinobarómetro (2008). Informe Latinobarómetro 2008. Santiago, Chile: Corporación Latinobarómetro.

_-_. (2009). Informe Latinobarómetro 2009. Santiago, Chile: Corporación Latinobarómetro.

_-_. (2010). Informe Latinobarómetro 2010. Santiago, Chile: Corporación Latinobarómetro.

———. (2011). Informe Latinobarómetro 2011. Santiago, Chile: Corporación Latinobarómetro.

Krugman, P. (2007). The Conscience of a Liberal. Estados Unidos: W. W. Norton y Company New York London.

Ocampo, J.A. (2001). Retomar la agenda del desarrollo. Revista de la Cepal, 74, 7-19. Recuperado de http://www.eclac.org/publicaciones/xml/5/19295/lcg2135e_Ocampo.pdf

Pérez, A. (2008). El método comparativo: Fundamentos y desarrollos recientes. Documento de Trabajo.

Programa de las Naciones Unidas para el Desarrollo PNUD (2011). Informe sobre Desarrollo Humano 2011. Sostenibilidad y equidad: un futuro mejor para todos. Santiago, Chile: Programa de Naciones Unidas para el Desarrollo (PNUD). 
Sen, A. (1997). Capital humano y capacidad humana. Cuadernos de Economía 29. Recuperado de http://portal.uam.es/portal/page/portal/UAM_ORGANIZATIVO/Departamentos/CienciaPoliticaRelacionesInternacionales/personal/irene_martin/pagina_personal_irene_martin/Ciencia\%20Politica\%202007-08/Sen\%20Capital\%20Humano\%20 y\%20Capacidad\%20Humana.pdf

- - . (1998). Las teorías del desarrollo a principios del siglo XXI. En L. Emmerij y J. Núñez del Arco (Eds.), El desarrollo económico y social en los umbrales del siglo XXI (pp. 73100). Washington, D.C, Estados Unidos: Banco Interamericano de Desarrollo.

- - . (2000). Development as Freedom. Gaceta Ecológica 55, 14-20. Recuperado de http://www2.ine.gob.mx/publicaciones/download/245.pdf 